\title{
Cyclo-oxygenase-2 (Cox-2) expression and resistance to platinum versus platinum/paclitaxel containing chemotherapy in advanced ovarian cancer
}

\author{
Gabriella Ferrandina*1, Franco O Ranelletti ${ }^{2}$, Enrica Martinelli ${ }^{1}$, \\ Amelia Paglia ${ }^{1}$, Gian Franco Zannoni ${ }^{3}$ and Giovanni Scambia ${ }^{4}$
}

\author{
Address: ${ }^{1}$ Gynecologic Oncology Unit, Catholic University, L.go Gemelli 8, 00168, Rome, Italy, ${ }^{2}$ Institute of Histology, Catholic University, L.go \\ A. Gemelli 8, 00168, Rome, Italy, ${ }^{3}$ Institute of Pathology, Catholic University, L.go A. Gemelli 8, 00168, Rome, Italy and ${ }^{4}$ Department of \\ Oncology, Catholic University, Contrada Tappino, Campobasso, Italy \\ Email: Gabriella Ferrandina* - gabriella.ferrandina@libero.it; Franco O Ranelletti - f.ranelletti@rm.unicatt.it; \\ Enrica Martinelli - enricamartinelli@rm.unicatt.it; Amelia Paglia - amelia.paglia@virgilio.it; Gian Franco Zannoni - gfzannoni@rm.unicatt.it; \\ Giovanni Scambia - gscambia@rm.unicatt.it \\ * Corresponding author
}

Published: II July 2006

BMC Cancer 2006, 6:182 doi:10.1 186/147|-2407-6-182

This article is available from: http://www.biomedcentral.com/I47/-2407/6//82

(c) 2006 Ferrandina et al; licensee BioMed Central Ltd.

This is an Open Access article distributed under the terms of the Creative Commons Attribution License (http://creativecommons.org/licenses/by/2.0), which permits unrestricted use, distribution, and reproduction in any medium, provided the original work is properly cited.

\begin{abstract}
Background: Cyclo-oxygenase-2 (COX-2), the key enzyme in the conversion of arachidonic acid to prostaglandins, is involved in critical steps of tumor onset and progression, and is a strong predictor of chemotherapy resistance and poor outcome in advanced ovarian cancer. To our knowledge, no data has been reported until now about the association between COX-2 status and response to different chemotherapy regimens.
\end{abstract}

Methods: A retrospective study was performed to investigate the association of COX-2 with outcome and response to platinum versus platinum/paclitaxel in 68 primary ovarian cancer. COX2 immunoreaction was performed on paraffin-embedded sections by using rabbit polyclonal antiserum against COX-2.

Results: In the overall series, COX-2 positivity was found in a statistically significant higher percentage of not responding cases than in patients responding to chemotherapy $(n=15 / 21 ; 71.4 \%$ versus $n=17 / 47 ; 36.1 \%$; $p$ value $=0.0072$ ). A higher percentage of COX-2 positivity was found in patients unresponsive $(\mathrm{n}=\mathrm{II} / \mathrm{I} ; 84.6 \%)$ versus patients responsive to platinum-based chemotherapy $(n=9 / 26 ; 34.6 \%)$. In cases administered platinum/paclitaxel, COX-2 positivity was found in 4 out of $8(50 \%)$ of un responsive versus 8 out of 21 (38.1\%) of responsive cases. Logistic regression analysis of parameters likely to affect response to treatment resulted in a $p$ value $=0.17$ for the interaction COX-2/type of treatment.

Conclusion: Although these findings need to be confirmed in a larger series, our study suggests a possible indication that there is a difference in the influence of COX-2 on response depending on treatment regimen. 


\section{Background}

Ovarian cancer represents the fifth leading cause of death for cancer in women [1]. More than $70 \%$ of cases present with advanced stage of disease at diagnosis and despite advances in cytoreductive surgery and establishment of carboplatin/paclitaxel combination as the standard chemotherapy regimen, intrinsic or acquired tumor chemoresistance remains the major determinant of chemotherapy failure and unfavourable clinical outcome [1,2].

Several molecular alterations have been proposed to support tumor resistance to cytotoxic drugs, such as the expression of MDR phenotype, mutation of $\mathrm{p} 53, \mathrm{bcl} 2$ overexpression [3-5], but only very recently it has been recognized that specific molecular or biological profiles might characterize tumor sensitivity to classes of agents with different mechanisms of action. For instance, mutation of p53 has been demonstrated to be strictly associated with platinum resistance in in vitro, and preclinical models as well as in humans $[4,6]$, while it is likely to sustain a higher chance of susceptibility to paclitaxel containing regimens $[7,8]$. Recently, expression of survivin, a member of the inhibitors of apoptosis protein [9], has been shown to be unrelated to response to cisplatin-based treatment, while its overexpression correlates with resistance to paclitaxel/platinum containing regimen in advanced ovarian carcinoma [10].

We showed that cyclooxygenase-2 (COX-2), the key enzyme in the conversion of arachidonic acid to prostaglandins, involved in critical steps of tumor onset and progression [10], is a strong predictor of chemotherapy resistance and poor outcome in advanced ovarian cancer, as well as cervical cancer patients [12-14]. These findings, also confirmed in other solid tumors, have also provided the rationale for the combination of selective COX-2 inhibitors with cytotoxic agents $[15,16]$.

To our knowledge, no data has been reported until now about the association between COX-2 status and response to different chemotherapy regimens.

The aim of the study was to investigate the association of COX-2 with outcome and response to platinum versus platinum/paclitaxel containing regimens as first line treatment in a single institutional series of primary untreated advanced ovarian cancer patients.

\section{Methods}

\section{Patient data}

A retrospective analysis of 68 ovarian cancer patients admitted to the Gynecologic Oncology Unit, Catholic University of Rome was planned. The study was approved by our Ethical Committee. Staging was performed according to FIGO classification. In order to make the analysis of the association with response to chemotherapy and outcome the most reliable, a very homogenous series of stage IIIC-IV ovarian cancer patients with measurable disease after primary surgery were included in the study.

Within 2-3 weeks after surgery, all patients underwent 4 to 6 cycles of cisplatin-based $\left(75-100 \mathrm{mg} / \mathrm{m}^{2}\right.$ for each cycle) or platinum/paclitaxel containing $\left(175 \mathrm{mg} / \mathrm{m}^{2}\right.$ for each cycle) chemotherapy. Response to chemotherapy was specifically assessed by gynecological examination, total body CT scan, analysis of CA125 levels. Response to treatment was recorded according to WHO criteria [17], as follows: complete response was defined as disappearance of all clinically detectable disease lesions for at least 4 weeks; partial response was defined as more than 50\% reduction in the sum of the products of the two largest perpendicular diameters of bidimensionally measurable lesions for at least 4 weeks; stable disease was defined as regression not meeting the aforementioned criteria for objective response; all other cases were considered to have progressive disease.

For the analysis of the association between COX-2 status and response to treatment patients were categorized in responsive (clinical complete and partial response) versus not responsive cases (no change/progression)

\section{Immunohistochemistry}

COX-2 immunoreaction was performed as previously described $[12,13]$. Briefly, four $\mu \mathrm{m}$ sections of representative formalin-fixed paraffin-embedded blocks from each case were deparaffinized in xylene, rehydrated, treated with $0.3 \% \mathrm{H}_{2} \mathrm{O}_{2}$ in methanol for $10 \mathrm{~min}$, and subjected to heat-induced epitope retrieval in microwave oven using the Dako ChemMate detection kit (DAKO, Glostrup, Denmark). Slides were then simultaneously processed for immunohistochemistry on the TechMate Horizon automated staining system (DAKO) using the Vectastain ABC peroxidase kit (Vector Laboratories, Burlingame, CA). Sections were incubated with normal rabbit serum for 15 min, then with rabbit polyclonal antiserum against COX2 (Cayman, Ann Arbor, MI, USA) diluted 1:300, for $1 \mathrm{~h}$. Negative controls were performed using non immunized rabbit serum or by omitting the primary antiserum.

The laboratory analysis of COX-2 and evaluation of immunohistochemical results were done without any prior knowledge of the clinical parameters by two different pathologists (FOR, GFZ) by means of light microscopy. Proportion of immunostained cells was scored at low magnification ( $5 \times$ objective lens) by evaluating the entire tumor area. In case of disagreement $(n=6 / 68$, $8.8 \%$ ), the sections were submitted to a rejoint evaluation. When tumor area with positive immunostaining was 
Table I: Clinico-pathological characteristics of the patients in the whole series, and according to type of chemotherapy

\begin{tabular}{|c|c|c|c|}
\hline Characteristics & No. of patients & $\begin{array}{l}\text { Platinum-containing } \\
\text { chemotherapy No. (\%) }\end{array}$ & $\begin{array}{c}\text { Platinum/paclitaxel containing } \\
\text { chemotherapy No. (\%) }\end{array}$ \\
\hline All cases & 68 & 39 & 29 \\
\hline \multicolumn{4}{|l|}{ Age (yrs) } \\
\hline$<60$ & 43 & $22(5 \mid .2)$ & 21 (48.8) \\
\hline$\geq 60$ & 25 & $17(68.0)$ & $8(32.0)$ \\
\hline \multicolumn{4}{|l|}{ FIGO Stage } \\
\hline IIIC & 50 & $31(62.0)$ & $19(38.0)$ \\
\hline IV & 18 & $8(44.4)$ & $10(55.6)$ \\
\hline \multicolumn{4}{|l|}{ Cytoreduction } \\
\hline $\mathrm{RT}<\mathrm{I} \mathrm{cm}$ & 18 & $12(66.7)$ & $6(33.3)$ \\
\hline $\mathrm{RT} \geq \mathrm{I} \mathrm{cm}$ & 50 & $27(54.0)$ & $7(14.0)$ \\
\hline \multicolumn{4}{|l|}{ Ascites } \\
\hline No & 16 & $8(50.0)$ & $8(50.0)$ \\
\hline Yes & 52 & $29(55.8)$ & $23(44.2)$ \\
\hline \multicolumn{4}{|l|}{ Histotype } \\
\hline Serous & 54 & $32(59.2)$ & $22(40.7)$ \\
\hline Endometrioid & 8 & $5(62.5)$ & $3(37.5)$ \\
\hline Undifferentiated & 6 & $2(33.3)$ & $4(66.7)$ \\
\hline Other & 3 & $2(66.7)$ & I (33.3) \\
\hline \multicolumn{4}{|l|}{ Grade } \\
\hline GI-2 & 10 & $8(80.0)$ & $2(20.0)$ \\
\hline G3 & 53 & $30(56.6)$ & $23(43.4)$ \\
\hline n.a. & 5 & & \\
\hline \multicolumn{4}{|l|}{ COX-2 } \\
\hline Negative & 36 & $19(52.8)$ & $17(47.2)$ \\
\hline Positive & 32 & $20(62.5)$ & $12(37.5)$ \\
\hline
\end{tabular}

in excess of $10 \%$ of total tumor area, the case was scored as positive.

\section{Statistical analysis}

Fisher's exact test or $\chi^{2}$ test were used to analyze the distribution of COX-2 positive cases according to clinico-pathological features and response to treatment.

Progression free survival (PFS) was calculated from the date of diagnosis to the date of progression or date last seen. Medians and life tables were computed using the product-limit estimate by the Kaplan and Meier method [18] and the log-rank test was employed to assess the statistical significance [19]. Stepwise logistic regression was used to analyze the role of clinico-pathological parameters as predictors of response to treatment and included the interaction COX-2/type of treatment.
Statistical analysis was carried out using SOLO (BMDP Statistical Software, Los Angeles, CA).

\section{Results}

Table 1 summarizes the clinico-pathological characteristics of cases in the whole series and according to the type of first line chemotherapy agents.

In the overall series median age was 57 years (range: $28-$ $81)$. Fifty cases (73.5\%) were stage IIIC and 18 (26.5\%) were stage IV disease.

Cytoreduction to residual tumor $0.5-1 \mathrm{~cm}$ was achieved in $18(26.5 \%)$ of cases, while cytoreduction to residual tumor $>1 \mathrm{~cm}$ was accomplished in 23 (33.8\%) of cases. In $27(39.7 \%)$ cases only multiple biopsies (exploratory laparotomy) were performed.

Table 2: Distribution of COX-2 positive cases according to response to chemotherapy

\begin{tabular}{llc}
\hline & \multicolumn{2}{c}{ Overall series } \\
\hline Response to chemotherapy & No. & COX-2 positive No.(\%) \\
\hline $\begin{array}{lll}\text { Responsive } \\
\text { Not responsive }\end{array}$ & 47 & $17(36.1)$ \\
& 21 & $15(71.4)$
\end{tabular}

*calculated by Fisher's exact test 
Table 3: Logistic regression analysis of clinico-pathological parameters, and COX-2 status as predictors of response to treatment in ovarian cancer patients

\begin{tabular}{lcc}
\hline Variable* & $\chi^{2}$ estimate & p value \\
\hline Stage & 0.11 & 0.7 \\
Residual tumor & 4.52 & 0.03 \\
COX-2 status & 2.04 & 0.09 \\
Type of chemotherapy & 2.10 & 0.11 \\
Interaction & 1.7 & 0.17
\end{tabular}

Response was subgrouped as follows: complete/partial vs no change of disease/progression.

*Variables were subgrouped as follows: stage III vs IV; residual tumor $<2 \mathrm{~cm}$ vs $\geq 2 \mathrm{~cm}$; negative vs positive COX-2 status; interaction COX-2 status/ type of treatment

Overall, COX-2 positivity was documented in 32/68 cases (47.0\%). In COX-2 positive cases the percentage of positive staining per total tumor area ranged from $15 \%$ to $45 \%$ (median value $20 \%$ ). Although the use of raw data provides more information, we decided to use the cut-off value in order to define different risk patient categories. There was no difference in the distribution of age, stage, residual tumor, and histopathological findings, in cases administered platinum versus platinum/paclitaxel containing chemotherapy. As far as response to chemotherapy is concerned, in the overall series 47 patients (69.1\%) were considered to be responsive to treatment, while 21 $(30.9 \%)$ patients were classified as no responders (Table 2).

In Table 2 the association between COX-2 status and response to chemotherapy in the overall series is also summarized: COX-2 positivity was found in a statistically significant higher percentage of not responding cases than in patients responding to chemotherapy $(n=15 / 21$; $71.4 \%$ versus $\mathrm{n}=17 / 47 ; 36.1 \%$; $\mathrm{p}$ value $=0.0072$ ).

Logistic regression analysis including variables likely to affect response to treatment showed that the extent of residual tumor at surgery maintained an independent role as predictor of resistance to treatment (Table 3 ). The $\mathrm{p}$ value of 0.17 of the interaction COX-2/type of treatment suggests that the role of COX-2 on differential response depending on different treatments needs to be clarified in a larger series of cases.

As shown in Table 4, in the group of patients administered platinum-based chemotherapy, COX-2 positivity was found in 11 out of $13(84.6 \%)$ of not responding patients versus 9 out of 26 (34.6\%) of responding patients. On the other hand, in cases administered platinum/paclitaxel containing chemotherapy, COX-2 positivity was found in 4 out o $8(50.0 \%)$ of unresponsive versus 8 out of 21 (38.1\%) of responsive cases.

\section{Survival analysis}

Follow up data were available for 68 patients. The median follow up was 33 months (range 4-214). During the follow up period, progression of disease was observed in 59 $(86.8 \%)$ cases. Figure 1 shows the progression free survival (PFS) curve in our population according to type of cytotoxic drugs in the first line treatment. There was no statistically significant difference of clinical outcome in patients administered platinum-based versus platinum/ paclitaxel containing chemotherapy $(\mathrm{p}$ value $=0.44)$,

\section{Discussion}

This is the first study investigating the association between COX2 status and susceptibility to chemotherapy according to type of cytotoxic agents used in first line treatment

Table 4: COX-2 positive cases according to response to chemotherapy in the two treatment groups

\begin{tabular}{|c|c|c|c|c|c|c|}
\hline \multirow[b]{2}{*}{ Response to CT } & \multicolumn{2}{|c|}{$\begin{array}{l}\text { Platinum-containing } \\
\text { chemotherapy }\end{array}$} & \multirow[t]{2}{*}{ P value* } & \multicolumn{2}{|c|}{$\begin{array}{c}\text { Platinum/paclitaxel containing } \\
\text { chemotherapy }\end{array}$} & \multirow[t]{2}{*}{ P value* } \\
\hline & No. & $\begin{array}{c}\text { COX-2 positive } \\
\text { No. (\%) }\end{array}$ & & No. & $\begin{array}{c}\text { COX-2 positive } \\
\text { No. (\%) }\end{array}$ & \\
\hline Responsive & 26 & $9(34.6)$ & & 21 & $8(38.1)$ & \\
\hline Not responsive & 13 & II (84.6) & 0.0057 & 8 & $4(50.0)$ & 0.43 \\
\hline
\end{tabular}

*calculated by Fisher's exact test 


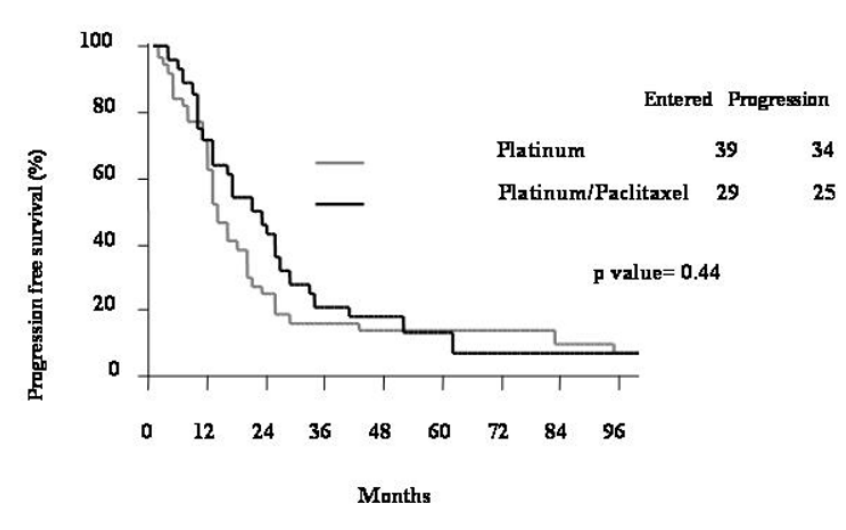

Figure I

Progression free survival (PFS) curve in ovarian cancer patients administered platinum containing versus platinum/ paclitaxel containing regimen.

of advanced ovarian cancer with measurable disease after first surgery.

Our findings suggest that there could be a difference in the influence of COX-2 expression depending on type of chemotherapeutic regimen (a difference greater in platinum-based treated cases), although a larger sample series is needed before a definitive conclusion can be drawn.

Our data seems to confirm the association between high COX-expression and poor chance of response to chemotherapy reported in ovarian and cervical tumors $[13,14,20]$. This finding remains to be clarified at biochemical level, although it is conceivable that the involvement of COX-2 in the crucial biochemical pathways of tumor cell biology might play a major role: indeed, COX2 has been reported to induce the antiapoptotic bcl-2 protein [21], and to be associated with neoangiogenesis in tumor bearing mice [22]. Since both inhibition of apoptosis and promotion of neoangiogenesis are strictly associated with chemotherapy resistance, it is conceivable that COX-2 expression could play a role as indicator of platinum resistance in ovarian cancer. Moreover, biochemical links between COX-2 and peptidic growth factor system alterations, which are renowned to be associated with resistance to several cytotoxic agents, have been documented [23,24]. Finally, very recent evidences demonstrated the relevant role of COX-2 in the inhibition of DNA damage induction of apoptosis mediated by p53 $[25,26]$; therefore, tumors overexpressing COX2 are likely to exhibit a reduction of wild-type p53 mediated apoptosis induced by DNA damaging chemotherapeutics, such as platinum compounds, alkylants and anthracyclines, often used in combination. Indeed, a direct association between high COX-2 content and overexpression/mutation of p53 has been reported in ovarian tumors, although conflicting data has been also provided [27-29].

Although the relatively small sample series has to be taken into account as a limit to the power of the analysis, it is conceivable that the addition of taxanes could hinder the COX-2 involvement in drug resistance, by acting on different molecular targets such as microtubule function or bcl$2[30,31]$.

It remains to be clarified why there was no significant difference in terms of response rate and clinical outcome in patients administered platinum versus platinum/paclitaxel containing regimens: even if the impact of the relatively small size of our sample series cannot be ruled out, an alternative intriguing working hypothesis is represented by the interference of taxanes with COX-2 promoted pathways. Indeed, it has been reported that the two clinically available taxanes, namely paclitaxel and docetaxel increase COX-2 expression by inducing mRNA transcription and stabilization [32-35]. Moreover, the addition of the specific COX-2 inhibitor celecoxib has been shown to abrogate the marked increase of $\mathrm{PGE}_{2}$ levels observed in non small cell lung cancer patients after carboplatin/paclitaxel administration [36]. Whether the potentiation of COX-2 promoted activities by taxanes could influence the overall sensitivity of ovarian cancer cells to the combination platinum/paclitaxel, by conceivably reducing the favourable impact of paclitaxel addition, remains to be verified. In this context, it is noteworthy that the vast majority of the studies exploring the association of taxanes with COX-2 inhibitors were able to document a synergistic antitumor activity in vitro and in vivo [33-35].

Finally, although the significance of our findings is not certain given that the standard first-line treatment for ovarian cancer is a combination of platinum with a taxane, we think that our data could provide, if confirmed in a wider series, the rationale to ask for the immunohistochemical assessment of COX-2 status as predictor of response to treatment, only in cases triaged to platinumbased therapy (including platinum/anthracycline or platinum/alkylants combinations, which are still a valid option in selected patients).

\section{Conclusion}

Although these findings need to be confirmed in a larger series, our study suggests a possible indication that there is a difference in the influence of $\mathrm{COX}-2$ on response depending on treatment regimen. The analysis of COX-2 expression in ovarian cancer tissues before and after carboplatin/paclitaxel treatment in patients submitted to exploratory laparotomy and interval debulking surgery after successful neoadjuvant treatment, would be helpful 
in order to assess whether this regimen can modulate COX-2 expression in vivo, as very recently reported by Altorki et al. [37].

\section{Competing interests}

The author(s) declare that they have no competing interests.

\section{Authors' contributions}

GF conceived the study, was the coordinator of the study, and drafted the manuscript

FOR participated in the design of the study

EM carried out the immunohistochemical analysis

AP was responsible for clinical surveillance

GFZ was responsible for paraffin embedded sections and for the evaluation and scoring of the immunohistochemistry

GS participated in the coordination of the study, and in the conception and drafting of the study.

All authors read and approved the final manuscript.

\section{Acknowledgements}

This work was financially supported by grants from Associazione Italiana per la Ricerca sul Cancro (A.I.R.C) and I.R.I.S-PCR-OG-ONLUS http:// www.iris-og.com.

\section{References}

I. Lundis SH, Murray T, Bolden S, Wingo PA: Cancer Statistics. CA Cancer J Clin 1998, 48:6-13.

2. Hoskins WJ, Perez CA, Young RC: Principles and Practice of Gynecologic Oncology. Philadelphia. PA: Lippincott Williams and Wilkins; 2000: 1005-1007.

3. Fink D, Nebel S, Aebi S, Zheng H, Cenni B, Nehme A, Christen RD, Howell SB: The role of DNA mismatch repair in platinum drug resistance. Cancer Res 1996, 56:488I-4886.

4. Righetti SC, Della Torre G, Pilotti S, Menard S, Ottone F, Pierotti MA, Lavarino C, Cornarotti M, Oriana S, Bohm S, Bresciani GL, Spatti G, Zunino $\mathrm{F}$ : A comparative study of $\mathrm{p} 53$ mutations, protein accumulation, and response to cisplatin based chemotherapy in advanced ovarian carcinoma. Cancer Res 1996, 56:689-693.

5. Murata T, Haisa M, Uetsuka H, Nobuhisha T, Ookawa T, Tabuchi $Y$, Shirakawa Y, Yamatsuji T, Matsuoka J, Nishiyama M, Tanaka N, Naomoto $Y$ : Molecular mechanisms of chemoresistance to cisplatin in ovarian cancer cells. Int J Mol Med 2004, I 3(6):865-868.

6. Ferrandina G, Fagotti A, Salerno G, Natali PG, Mottolese M, Maneschi F, De Pasqua A, Benedetti Panici P, Mancuso S, Scambia G: P53 overexpression is associated with cytoreduction and response to chemotherapy in ovarian cancer. Br / Cancer 1999, 8 I:733-740.

7. Lavarino C, Pilotti S, Oggionni M, Gatti L, Perego P, Bresciani G, Pierotti M, Scambia G, Ferrandina G, Fagotti A, Mangioni C, Lucchini $V$, Vecchione F, Bolis G, Scarfone G, Zunino F: p53 status and response to platinum/paclitaxel based chemotherapy in advanced ovarian carcinoma. J Clin Oncol 2000, 18:3936-3945.

8. Wahl AF, Donaldson KL, Fairchild C, Lee FY, Foster SA, Demers GW, Galloway DA: Loss of normal p53 function confers sensitization to Taxol by increasing G2/M arrest and apoptosis. Nat Med 1996, 2:72-79.
9. La Casse EC, Baird S, Korneluk RG, MacKenzie AE: The inhibitors of apoptosis (IAPs) and their emerging role in cancer. Oncogene 1998, 17:3257-3259.

10. Zaffaroni N, Pennati M, Colella G, Perego P, Supino R, Gatti L, Zunino $F$, Daidone MG: Expression of the antipoptotic gene survivin correlates with taxol resistance in human ovarian cancer. Cell Mol Life Sci 2002, 59:1406-1412.

II. Chandrasekharan NV, Simmons DL: The cyclooxygenases. Genome Biology 2004, 5:24I-247.

12. Ferrandina G, Lauriola L, Zannoni GF, Fagotti A, Fanfani F, Legge F, Maggiano N, Gessi M, Mancuso S, Ranelletti FO, Scambia G: Increased cyclooxygenase-2 (COX-2) expression is associated with chemotherapy resistance and outcome in ovarian cancer patients. Ann Oncol 2002, 13:1205-121I.

13. Ferrandina G, Ranelletti FO, Legge F, Gessi M, Salutari V, Distefano MG, Lauriola L, Zannoni GF, Martinelli E, Scambia G: Prognostic role of the ratio between cyclooxygenase-2 (COX-2) in tumor and stroma compartments in cervical cancer. Clin Cancer Res 2004, 10(9):31 I7-3123.

14. Ferrandina G, Lauriola L, Distefano MG, Zannoni GF, Gessi M, Legge F, Maggiano N, Mancuso S, Capelli A, Scambia G, Ranelletti FO: Increased cyclooxygenase-2 (COX-2) expression is associated with chemotherapy resistance and poor survival in cervical cancer patients. J Clin Oncol 2002, 20:973-98I.

15. Altundag O, Altundag K, Morandi P, Gunduz M: Cyclooxygenase-2 inhibitor and cisplatin combination as radiosensitizer in the treatment of head and neck cancer patients. Ann Oncol 2004, I5: 1444-1445.

16. Awara WM, El-Sisi AZ, El-Sayad ME, Goda AE: The potential role of cyclooxygenase-2 inhibitors in the treatment of experimentally induced mammary tumor: does celecoxib enhance the anti-tumor activity of doxorubicin? Pharmacol Res 2004, 50:487-498.

17. World Health Organization: WHO handbook for reporting results of cancer treatment. WHO, Geneva, Offset publication no.48; 1979:16-2I.

18. Kaplan E, Meyer P: Non parametric estimation from incomplete observations. J Am Statist Association 1958, 53:457-48I.

19. Mantel N: Evaluation of survival data and two new rank order statistics arising in its consideration. Cancer Chemother Rep 1966, 50:163-170.

20. Raspollini MR, Amunni G, Villanucci A, Boddi V, Baroni G, Taddei A, Taddei GL: Expression of inducible nitric oxide synthase and cyclooxygenase- 2 in ovarian cancer: correlation with clinical outcome. Gynecol Oncol 2004, 92(3):806-8I2.

21. Liu XH, Yao S, Kirschenbaum A, Levine AC: NS-398, a selective cyclooxygenase- 2 inhibitor, induces apoptosis and down-regulates bcl-2 expression in LNCap cells. Cancer Res 1998, 58:4245-4249.

22. Liu XH, Kirschenbaum A, Yao S, Lee R, Holland JF, Levine AC: Inhibition of cyclooxyenase-2 suppresses angiogenesis and the growth of prostate cancer in vivo. J Urology 2000, 164:820-825.

23. Vadlamudi R, Mandal M, Adam L, Steinbach G, Mendelsohn J, Kumar $R$ : Regulation of cyclooxygenase-2 pathway by HER2 receptor. Oncogene 1999, 18:315-324.

24. Kinoshita T, Takahashi Y, Sakashita T, Inoue H, Tanabe T, Yoshimoto T: Growth stimulation and induction of epidermal growth factor receptor by overexpression of cyclooxygenase $I$ and 2 in human colon carcinoma cells. Biochim Biophys Acta 1999, 1438: I 20-130.

25. Choi EM, Heo Jl, Oh Jl, Kim YM, Ha KS, Kim JI, Han JA: COX-2 regulates p53 activity and inhibits DNA damage-induced apoptosis. Biochem Biophys Res Commun 2005, 328(4): I I07-II I 2.

26. Corcoran CA, He Q, Huang Y, Sheikh MS: Cycloxygenase-2 interacts with $\mathrm{p} 53$ and interferes with p53-dependent transcription and apoptosis. Oncogene 2005, 24:1634-1640.

27. Erkinheimo TL, Lassus $H$, Finne $P$, van Rees BP, Leminen A, Ylikorkala $O$, Baglund C, Butzow R, Ristimaki A: Elevated cyclooxygenase-2 expression is associated with altered expression of $\mathrm{p} 53$ and SMAD4, amplification of HER-2/neu, and poor outcome in serous ovarian carcinoma. Clin Cancer Res 2004, I 0(2):538-545.

28. Shigemasa K, Tian X, Gu L, Shiroyama Y, Nagai N, Ohama K: Expression of cyclooxygenase-2 and its relationship to $\mathrm{p} 53$ accumulation in ovarian adenocarcinomas. Int J Oncol 2003, 22:99-105.

29. Ali-Fehmi R, Che M, Khalifeh I, Malone JM, Morris R, Lawrence WD, Munkarah AR: The effect of cyclooxygenase-2 expression on 
tumor vascularity in advanced stage ovarian serous carcinoma. Cancer 2003, 98(7): I423-I429.

30. Jordan MA, Wilson L: Microtubules and actin filaments: dynamic targets for cancer chemotherapy. Curr Opin Cell Biol 1998, 10:123-130

31. Ferlini C, Raspaglio G, Mozzetti S, Distefano M, Filippetti F, Martinelli E, Ferrandina G, Gallo D, Ranelletti FO, Scambia G: Bcl-2 down-regulation is a novel mechanism of paclitaxel resistance. Mol Pharmacol 2003, 64:5I-58.

32. Subbamaraiah K, Marmo TP, Dixon DA, Dannemberg AJ: Regulation of Cyclooxygenase-2 mRNA stability by taxanes. J Biol Chem 2003, 278(39):37637-37647.

33. Hida T, Kozaki K, Ito H, Miyaishi O, Tatematsu Y, Suzuki T, Matsuo $Y$, Sugiura T, Ogawa M, Takahashi T, Takahashi T: Significant growth inhibition of human lung cancer cells both in vitro and in vivo by the combined use of a selective cyclooxygenase-2 inhibitor, JTE-522, and conventional anticancer agents. Clin Cancer Res 2002, 8:2443-2447.

34. Merchan JR, Jayaram DR, Supko JG, He X, Bubley GJ, Sukhatme VP: Increased endothelial uptake of paclitaxel as a potential mechanism for its antiangiogenic effects: potentiation by COX-2 inhibition. Int J Cancer 2005, I I 3:490-498.

35. Dandekar DS, Lopez M, Carey RI, Lokeshwar BL: Cyclooxygenase2 inhibitor celecoxib augments chemotherapeutic druginduced apoptosis by enhancing activation of caspase- 3 and 9 in prostate cancer cells. Int J Cancer 2005, I I (3):484-492.

36. Altorki NK, Keresztes RS, Port JL, Libby DM, Korst RJ, Flieder DB, Ferrara CA, Yankelevitz DF, Subbamaraiah K, Pasmantier MW, Dannemberg AJ: Celecoxib, a selective cyclooxygenase- 2 inhibitor, enhance the response to preoperative paclitaxel and carboplatin in early stage non small cell lung cancer. I Clin Oncol 2003, 2 I(14):2645-2650.

37. Altorki NK, Port JL, Zhang F, Goliijanin D, Thaler AJ, Duffield-Lilico AJ, Subbamaraiah K, Dannemberg AJ: Chemotherapy induces the expression of cyclooxygenase-2 in non small cell lung cancer. Clin Cancer Res 2005, I I:4191-4197.

\section{Pre-publication history}

The pre-publication history for this paper can be accessed here:

http://www.biomedcentral.com/1471-2407/6/182/pre pub

\section{Publish with Biomed Central and every scientist can read your work free of charge}

"BioMed Central will be the most significant development for disseminating the results of biomedical research in our lifetime. "

Sir Paul Nurse, Cancer Research UK

Your research papers will be:

- available free of charge to the entire biomedical community

- peer reviewed and published immediately upon acceptance

- cited in PubMed and archived on PubMed Central

- yours - you keep the copyright 